\title{
Corrigendum: Gene expression-based high-throughput screening (GE-HTS) and application to leukemia differentiation
}

K Stegmaier, K N Ross, S A Colavito, S O’Malley, B R Stockwell \& T R Golub

Nat. Genet. 36, 257-263 (2004).

The GEO accession number for the array data is GSE995.

\footnotetext{
Erratum: Assessing the validity of the association between the SUMO4 M55V variant and risk of type 1 diabetes

D J Smyth, J M M Howson, C E Lowe, N M Walker, A C Lam, S Nutland, J Hutchings, E Tuomilehto-Wolf, J Tuomilehto, C Guja, C IonescuTîrgovişte, D E Undlien, K S Rønningen, D Savage, D B Dunger, R C J Twells, W L McArdle, D P Strachan \& J A Todd

Nat. Genet. 37, 110-111 (2005).

The authors' affiliations were mistakenly omitted. A complete list of authors and their affiliations follows.

Deborah J Smyth ${ }^{1}$, Joanna M M Howson ${ }^{1}$, Christopher E Lowe ${ }^{1}$, Neil M Walker ${ }^{1}$, Alex C Lam ${ }^{1}$, Sarah Nutland ${ }^{1}$, Jayne Hutchings ${ }^{1}$, Eva Tuomilehto-Wolf ${ }^{2}$, Jaakko Tuomilehto ${ }^{2-4}$, Cristian Guja ${ }^{5}$, Constantin Ionescu-Tîrgovişte ${ }^{5}$, Dag E Undlien ${ }^{6}$, Kjersti S Rønningen ${ }^{7}$, David Savage $^{8}$, David B Dunger ${ }^{9}$, Rebecca C J Twells ${ }^{1}$, Wendy L McArdle ${ }^{10}$, David P Strachan ${ }^{11}$ \& John A Todd ${ }^{1}$

${ }^{1}$ Juvenile Diabetes Research Foundation/Wellcome Trust Diabetes and Inflammation Laboratory, Cambridge Institute for Medical Research, University of Cambridge, Wellcome Trust/MRC Building, Addenbrooke's Hospital, Hills Rd, Cambridge, UK. ${ }^{2}$ Diabetes and Genetic Epidemiology Unit, National Public Health Institute, University of Helsinki, Helsinki, Finland. ${ }^{3}$ Department of Public Health, University of Helsinki, Helsinki, Finland. ${ }^{4}$ South Ostrobotnia Central Hospital, Seinäjoki, Finland. ${ }^{5}$ Clinic of Diabetes, Institute of Diabetes, Nutrition and Metabolic Diseases 'N. Paulescu', Bucharest, Romania. ${ }^{6}$ Institute and Department of Medical Genetics, Ulleval University Hospital, University of Oslo, Oslo, Norway. ${ }^{7}$ Laboratory of Molecular Epidemiology, Division of Epidemiology, Norwegian Institute of Public Health, Oslo, Norway. ${ }^{8}$ Department of Medical Genetics, Queen's University Belfast, Belfast City Hospital, Belfast, Northern Ireland. ${ }^{9}$ Department of Paediatrics, University of Cambridge, Addenbrooke's Hospital, Cambridge, UK. ${ }^{10}$ Avon Longitudinal Study of Parents and Children, University of Bristol, Bristol, UK. ${ }^{11}$ Department of Community Health Sciences, St George's Hospital Medical School, London, UK. Correspondence should be addressed to J.A.T. (john.todd@cimr.cam.ac.uk).
}

Corrigendum: Low LDL cholesterol in African Americans resulting from frequent nonsense mutations in PCSK9

J Cohen, A Pertsemlidis, I K Kotowski, R Graham, C K Garcia \& H H Hobbs

Nat. Genet. 37, 161-165 (2005).

The 25-year-old offspring of the proband in Figure 3a is a woman. 